\title{
State Stimulation of Cluster Initiatives in Business
}

\section{Tatiana Koryakina}

Financial University under the Government of the Russian Federation, Lipetsk branch, Lipetsk Russia, Yulia loda - Lipetsk State Technical University, Lipetsk, Russia

\section{Tatiana Litvinova}

Volgograd State Agrarian University, Volgograd, Russia, Mariya F Serebryakova - Volgograd State Agrarian Univercity, Volgograd, Russia

\section{Doi:10.5901/mjss.2016.v7n1p133}

\begin{abstract}
The authors substantiate the necessity for state stimulation of cluster initiatives in entrepreneurship, study the experience of developed countries in the sphere of state stimulation of cluster initiatives in entrepreneurship, and give recommendations for improving the system of state stimulation of cluster initiatives in entrepreneurship. As a result of the research, the authors conclude that at present, innovational economy is an economic system which functions on the basis of business networks, as it is this model that provides innovational cooperation between specialists of various scientific and technical spheres, between organizations various sizes (large, medium, and small), and between groups of companies of various types of economic activities. Cluster strategy in modern global practice is one of the most important tools of state policy of increasing competitiveness of national economies. Thus, the most competitive spheres develop on the basis of cluster principle, and support for cluster building stipulates the growth of competitiveness of economies of the countries on the whole. That's why state stimulation of cluster initiatives in business stipulates the development of entrepreneurship and of national economy on the whole.
\end{abstract}

Keywords: innovational system, state stimulation, cluster initiative, entrepreneurship.

\section{Introduction}

Transition to innovational development of economy is impossible without formation and development of innovational systems. This requires creation of effective mechanisms of functioning of system of interaction and collaboration relations between regional companies, research organizations, and state establishments; provision of close contacts within local business elite, i.e., development of formal and informal network organizations, provision of active inflow of venture capital, etc., which could be provided within implementation of cluster initiatives.

One of the founders of the concept of innovational system was Professor Philip Cooke from the Center for Special Research of Cardiff University (Great Britain). He suggested formal three-part definition of innovational system as a "set of knots in innovational chain including generating knowledge of company, organizations and enterprises using (applying) this knowledge, and various structures which perform specialized intermediary functions: infrastructural provision, financing of innovational projects, their market evaluation political support" (Cooke \& Morgan, 1993).

Due to the fact that creation of the most important elements of innovational process (for example, generation of innovations, transfer of technologies, etc.) is provided in the process of cluster functioning, the problem of search for effective tools of state stimulation of cluster initiatives in business becomes rather topical, which is described below.

The purpose of the research is analysis of existing system of state stimulation of cluster initiatives in business, determination of perspectives, and development of recommendations as to its perfection. The set goal predetermined the following tasks of the research:

- study of experience of developed countries in the sphere of state stimulation of cluster initiatives in business for determination of conditions of success of state support for cluster development;

- determination of key problems of formation and functioning of cluster and of the most effective tools for state stimulation of cluster initiatives in business;

- determination of the most important directions of support for innovational cluster initiatives;

- analysis of tasks, mechanisms, and tools of state innovational cluster policy; 
- study of institutional elements which ensure innovational development in cluster entities.

The purpose of the research is achieved with the help of use of systemic analysis method. This method is selected because it allows viewing national economy as a system, the structural elements of which are business and state. These elements interact in the process of state stimulation of cluster initiatives in business. The selected method is convenient for determination of causal connections of the use of various tools of state cluster policy.

\section{Experience of Developed Countries in the Sphere of State Stimulation of Cluster Initiatives in Business}

Foreign research shows that in transitional developing countries the initiators of cluster development are government (32\%), business (27\%), business and government (25\%) (The Cluster Initiative Greenbook, 2015). At that, state support for cluster development achieves success when:

- state reacts timely to cluster's needs, taking into account entrepreneurial, geographical, and historical context;

- state is capable of increasing the role of main factor conditions - even the role of chance could be successfully used with concentration of state efforts and finances;

- state methods of regulation are concentrated on support for various stages of cluster life cycles;

- state provides necessary infrastructure for cluster development, trying to foresee the needs of business structures and not to follow the path of business;

- state support is concentrated on company-leader, the core of cluster.

At that, state has to guarantee the safety of supplying, facilitate the appearance of new suppliers and buyers around a new leader, and, besides, stipulate the formation of new leading companies. Foreign experience of using cluster initiatives for the purpose of stimulation of innovative activities shows that economic policy that is based on clusters differs from traditional approaches (Xavier et al., 2015).

Its difference consists in the fact that, firstly, all clusters are very important to some extent, as efficiency within clusters determines living standards of country or region. Secondly, cluster policy is not narrow but wide efforts of authorities for the development of economy; it is a tool of politics, aimed at creation of engines for economic growth. Thirdly, cluster policy is aimed at stimulation of innovations through stimulation of competition development (Reveiu \& Dârdală, 2015).

One of the significant problems of formation and functioning of cluster is determining the level of expenses necessary for supporting their creation. Experience of the countries which successfully conduct cluster policy (for example, France - in creation of competitiveness poles) shows that state always participates in clusters creation. Cluster can be built according to three scenarios: "top-down", "bottom-up", and mixed variant. For the current stage of Russia's economy development, the most perspective is mixed scenario. At that, cluster can be created with various forms of financing: on the basis of budget resources, own funds of main enterprise (core) of cluster, or in the basis of joint usage of both forms of financing (Geldes et al., 2015).

The most acceptable method of state influence in the formation of clusters is the method of integration of cluster approach into innovational policy. This is due to the fact that, firstly, it uses the tools of direct and indirect financial support for innovational projects in the sphere of infrastructural provision of innovational entrepreneurship. Secondly, the method is based on the improvement of institutional environment of entrepreneurship through formation of multi-level innovational infrastructure. Experts distinguish two main models within which cluster policy is conducted in particular countries: liberal (USA, Great Britain, Australia, Canada) and conductorial, or combined (France, Korea, Singapore, Japan, Sweden, Finland, Slovenia) (Mihajlović, 2014).

Thirdly, in this approach, the tasks of state power bodies in solution of problems of network organization of entrepreneurial structures are related to clustering of small and medium business. Federal bodies can effectively perform the following functions: analytical, initiating, consulting, supporting, coordination, intermediary, and monitoring of development. Functions of regional authorities include methods of indirect stimulation of cluster development as measures of direct regulation and management.

The issue of increase of the share of regions and business in implementation of cluster initiatives is topical not only in Russia but in other countries of the world. This, the research by the authors of Cluster Initiative GreenBook showed that most of the forming clusters were financed by the state. Thus, out of 200 cluster initiatives, which are implemented by various subjects in the world (among which the share of companies was $25 \%$, state $-32 \%$, scientific society - $5 \%$, jointly state ad business - 35\%) the share of state funds constituted $54 \%$, companies - $18 \%$, scientific society $-1 \%$, jointly state and business - 25\%, and 2\% account for international organizations (Solvell et al., 2015).

Foreign experience shows that combination of priority and attention to principles of competition allows increasing 
the efficiency of state measures. In particular, in Germany, the Bioregio program saw the half of the staff of one third of companies involved in R\&D. And $44 \%$ of the companies, included into the Innoregio program, could apply for the patent, while $40 \%$ - could issue new products.

In developed countries, the main tool of state in the sphere of activization of cluster development is financing of complex cluster programs. It is about state's providing financial support for programs which unite business and scientific \& educational establishments. These programs unite infrastructural projects (which is peculiar for implementation of industrial policy) and innovation-oriented projects.

\section{Recommendations for Improvement of System of State Stimulation of Cluster Initiatives in Business}

Cluster policy should be aimed at solution of two main problems: stimulation of cluster initiatives; creation of favorable environment for existing clusters.

Cluster initiative is coordinated actions, aimed at the increase of competitiveness and growth of regional sectorial cluster with attraction and direct participation of key members of cluster - enterprises, associations, scientific \& educational establishment, etc. Effectiveness of this policy is achieved by means of integration of cluster approach to regional strategies and programs of territories development. At that, cluster approach is a special methodological basis of innovational policy, uniting industrial and scientific \& technical policy, policy of support for small entrepreneurship, and regional policy.

The most important directions of support for innovational cluster initiatives are development of corresponding scientific \& technical potential through implementation of focused financial support for R\&D, creation of scientific and technological parks and centers for technologies transfer, and support for commercialization of R\&D results.

The second direction is connected to support for business initiatives and supposes creation of business incubators for cluster profile and of venture funds, support for access to credit resources, leasing of equipment on special terms, certain tax preferences, subsidies for using state property, and reduction of administrative barriers. Mechanisms and tools of state innovational cluster policy are:

- regional innovational strategies and programs (including interdepartmental and transregional ones, including mid-term);

- state support for commercialization of results of scientific research and applied developments;

- creation of favorable economic and investment climate for functioning of innovational industrial enterprises of the region;

- cooperation between scientific and educational establishments, organizations of innovational structure, and industrial enterprises of region;

- monitoring of development of innovational and cluster-oriented activities in region, etc.

Cluster can be presented as special "growth poles", which is caused by multidimensionality of their role, in particular:

- territorial localization of clusters makes cluster policy one of the priorities of strategies of socio-economic development of regions;

- sectorial specifics of cluster development makes them an important tool of sectorial policy;

- supporting cluster initiatives allows implementing the mission of national and regional institutes of development for formation of infrastructure, providing necessary conditions for development of investment and innovational projects.

Foreign experience shows that effectiveness of cluster policy which is conducted in regions in innovation-oriented industrial sphere can be checked by variety of circumstances, in particular:

- insufficient level of coordination of actions of various parties which take part in formation and implementation of innovational policy, which leads to irregularity of financing within the period of cluster creation and low profitability of invested resources;

- low intensity of scientific \& technical activity as to key direction of cluster development, including educational component;

- low level of accessibility of specialized services for development of newly founded technological companies, etc.

As opposing measures to the above mentioned negative circumstances for quickening of the creation of innovational industrial clusters in the Common Economic Space countries, the following ones can be taken:

- state subsidies for small and medium enterprises which cooperate with universities and scientific centers; 
- state subsidies for purchase of know-how;

- preferential credits for expansion of R\&D and production activity for perspective enterprises within clusters;

- financing the projects of creation of innovational infrastructure in region;

- creation of additional subjects of financial infrastructure.

Perspectives of innovational development of country largely depend in efficiency of state policy on stimulation of cluster initiatives in business. State stimulation of cluster initiatives in business is aimed at solution of the following main tasks:

- determining and implementing priorities of innovational policy, effective innovational projects, and programs;

- developing and implementing measures for effective development and usage of innovational potential, science-intensive technologies, innovational infrastructure, and, finally, issue of new and competitive products;

- implementing measures for support for promoting new products in the markets, including support for export of new products and (or) new technological processes, created by Russian manufacturers;

- support for creation and implementation of innovations, new achievements in education, healthcare, culture, housing and utilities infrastructure, organization and management of economy;

- provision of cooperation between science, education, production, and financial sphere for development of innovative activities;

- strengthening of state support for subjects and processes of innovative activities through setting the order and mechanisms of forecasting, financing, economic stimulation, and organization of monitoring of innovations in all spheres of cluster development.

Implementation of measures of state stimulation of cluster initiatives in entrepreneurship is aimed, firstly, at solution of strategic task of development of competitive production and scientific \& technical potential of enterprise within cluster entity and, secondly, at provision of sustainable development of cluster.

The tasks of state stimulation of cluster initiatives in business include not only solution of local tasks of innovational character on the basis of using potential of scientific \& technical organizations but stimulation of activity of enterprises within cluster, overcoming disunity of various economic subjects, development of various mechanisms of provision of their economic integration. In its turn, this supposes development of clear strategy, setting goals and priorities of development of innovative activities in cluster entity. Institutional elements which provide innovational development in cluster entities are the following (Popkova et al., 2015):

- innovational strategies and programs (including interdepartmental and transregional, including mid-term);

- mechanisms of state support for commercialization of results of scientific research and experimental developments;

- favorable economic and investment climate for functioning of innovational enterprises of cluster;

- cooperation between scientific organizations, organizations of innovational infrastructure, and industrial enterprises of cluster;

- monitoring of development of innovative activities in cluster, etc.

Increasing interest to regional clusters and innovational systems in recent years reflects the realization of importance of regional resources in stimulation of competitiveness and innovational potential of industrial enterprises. Sense of clustering consists in the following (Popkova \& Tinyakova, 2013a):

- clusters in the context of development strategies - territorial localization of clusters makes cluster policy one of the priorities of strategies of socio-economic development of regions;

- clusters in the context of sectorial policy - sectorial specifics of development of clusters makes them an important tool of sectorial policy;

- clusters in the context of development institutes activities - support for cluster initiatives allows implementing the mission if development institutes for formation of infrastructure, providing necessary preconditions for development of investment and innovational projects.

Role of clusters in economy consists in the fact that they facilitate the intensification of innovative activities of economic subjects. This is proved by research conducted in countries in which cluster policy is a part of innovational policy (Carneiro et al., 2015). A large part of implemented cluster programs refers to regional policy.

The above mentioned is confirmed by the results of study of 200 cluster initiatives all around the world, conducted by the authors of the Cluster Initiative GreenBook (Solvell et al., 2015). In this book, innovative activities and distribution of technologies, together with development of social capital (formation of networks), expansion (growth) of companies, teaching, commercial partnership, and lobbying are determined as an important category of purposes of cluster work. Purposes of cluster initiative, related to innovative activities and technologies distribution, are presented in Table 1 
(Popkova \& Tinyakova, 2013b).

Table 1. Innovative activities and technologies distribution as a purpose of cluster initiative

\begin{tabular}{|ll|}
\hline & Measures for purpose achievement \\
\hline Popular purposes (75\% of cluster initiatives) & $\begin{array}{l}\text { Support for increase of competitiveness } \\
\text { Creation of new technologies }\end{array}$ \\
\hline Regarding popular purposes (50\% of all cluster initiatives) & $\begin{array}{l}\text { Analysis of directions of scientific \& technical progress } \\
\text { Distribution of cluster technologies } \\
\text { Improvement of production process }\end{array}$ \\
\hline Rare purposes (25\% of all cluster initiatives) & Setting the standards of technical regulation
\end{tabular}

Cluster approach is a special methodological basis for innovational policy, uniting industrial and scientific \& technical policies, policy of support for small business, and regional policy.

As effective tools for state stimulation of cluster initiatives into business, this research offers the following ones:

- grants for creation of innovational company;

- subsidies to innovational companies for R\&D, production design, design, purchase of cars and equipment, related to technological innovations, purchase of patents and licenses, software; teaching and training staff who work with innovations and marketing research; certification and patenting;

- subsidies for participation of exhibit events;

- creation of organizations and provision of activities of organizations which form the infrastructure of support for small and medium business subjects and help small and medium enterprises, including centers for technologies commercialization, centers for collective access to high-tech equipment, engineer centers, centers of prototyping and industrial design, centers for technological competencies, centers for subcontracting, and centers for technologies transfer;

- compensation for expenses of subjects of small and medium business for technological audit (evaluation of current technological level of company, quality management system, system of projecting and development of new products, as compared to rivals in Russia and abroad).

- joint development of unified standards regarding products and suppliers;

- organization of collective marketing projects and projects for joint entry into new markets;

- organization of joint projects in the sphere of cost reduction, quality increase, logistics, informational \& communicational technologies, etc.;

- conduct of benchmarking, organization of works for provision of correspondence of cluster's enterprises to consumers' requirements for the purpose of entry into new sales markets.

\section{Conclusion}

It should be noted that significant role of clusters in solving fundamental tasks of national and regional economies determines the search for new forms of interaction of private sector, state, scientific \& educational organizations, and public organizations which provide implementation of mutual profits, and not just solving problems of particular companies or spheres.

Effectiveness of state stimulation of cluster initiatives in business depends on the quality of coordination of actions of various state structures which participate in formation and implementation of cluster policy. In absence of proper coordination of program measures, there may be observed irregularity of financing during the program active period and low indicators of profitability of invested assets.

\section{References}

Carneiro, J., Matos, N., Husted, B. (2015). Free markets and social inclusion: Toward a common goal. Journal of Business Research, 68 (2), 173-176.

Cooke P. \& Morgan K. (1995). The network paradigm: new departures in corporate and regional development. Environment and Planning, 11, 543-564;

Geldes, C., Felzensztein, C., Turkina, E.,Durand, A. (2015). How does proximity affect interfirm marketing cooperation? A study of an agribusiness cluster. Journal of Business Research, 68 (2), 263-272.

Mihajlović, I. (2014). Possibilities for development of business cluster network between SMEs from Visegrad countries and Serbia. 
Serbian Journal of Management, 9 (2), pp. 145-148.

Popkova, E.G. \& Tinyakova V.I. (2013a). New Quality of Economic Growth at the Present Stage of Development of the World Economy. World Applied Sciences Journal, 5, 617-622.

Popkova, E.G. \& Tinyakova, V.I. (2013b). Drivers and Contradictions of Formation of New Quality of Economic Growth. Middle-East Journal of Scientific Research, 11, 1635-1640.

Popkova, E.G., S.S. Morkovina, E.V. Patsyuk, E.A. Panyavina \& Popov, E.V. (2013). Marketing Strategy of Overcoming of Lag in Development of Economic Systems. World Applied Sciences Journal, 5, 591-595.

Reveiu, A., Dârdală, M. (2015). Influence of cluster type business agglomerations for development of entrepreneurial activities study about Romania. Amfiteatru Economic, 17 (38), 107-119.

Solvell O., Lindqvist G., Ketels C. (2015). The Cluster Initiative GreenBook. URL: http//www. Cluster-research org.

The Cluster Initiative Greenbook: New Finding on the Process of Cluster-Based Economic Development (2015). URL: http//www.ivorytower.se/greenbook/general.html.

Xavier Molina-Morales, F., Belso-Martínez, J.A., Más-Verdú, F., Martínez-Cháfer, L. (2015). Formation and dissolution of inter-firm linkages in lengthy and stable networks in clusters. Journal of Business Research, 68 (7), 1557-1562 